\title{
MONITORAMENTO DA COMPOSIÇÃO EM ÉSTERES DO BIODIESEL DO ÓLEO DE AMÊNDOA DA MACAÚBA (Acrocomia aculeata (Jacq.) Lodd. ex Mart.) EM CONTATO DIRETO COM O AÇO CARBONO E O AÇO CARBONO GALVANIZADO
}

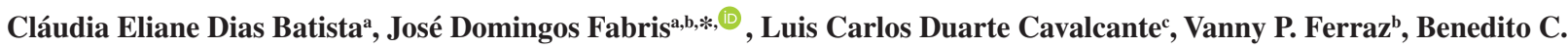 \\ Andrade Junior ${ }^{d}$, José Domingos Ardissone, Leandro R. de Lemos ${ }^{\mathrm{f}}$ e Sandra M. Damasceno ${ }^{\mathrm{a}}$ \\ ${ }^{a}$ Universidade Federal dos Vales do Jequitinhonha e Mucuri, 39100-000 Diamantina - MG, Brasil

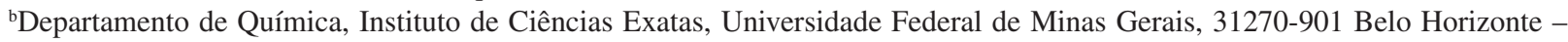 \\ MG, Brasil \\ 'Departamento de Arqueologia, Centro de Ciências da Natureza, Universidade Federal do Piauí, 64049-550 Teresina - PI, Brasil \\ dUniversidade Federal de Minas Gerais, 31270-901 Belo Horizonte - MG, Brasil \\ ${ }^{e}$ Centro de Desenvolvimento da Tecnologia Nuclear, Comissão Nacional de Energia Nuclear, Campus UFMG Pampulha, $31270-$ \\ 900 Belo Horizonte - MG, Brasil \\ fDepartamento de Química, Universidade Federal dos Vales do Jequitinhonha e Mucuri, 39100-000 Diamantina - MG, Brasil
}

Recebido em 12/12/2018; aceito em 31/01/2019; publicado na web em 17/04/2019

\begin{abstract}
MONITORING THE COMPOSITION IN ESTERS OF THE BIODIESEL FROM THE MACAÚBA (Acrocomia aculeata (Jacq.) Lodd. ex Mart.) KERNEL OIL PUT IN DIRECT CONTACT WITH CARBON STEEL AND GALVANIZED CARBON STEEL. The oil from the macaúba (Acrocomia aculeata) fruit, a native palm in Brazil, has a real potential for the industrial production of biodiesel. This report describes an experimental work devoted to monitor the chemical behavior of the fatty acid methyl esters from oil of the macaúba fruit kernel and the leaching of metal elements into the biodiesel put in contact with the ASTM A283 grade C and API X65 carbon steels, used to build fuel storage tanks and biodiesel pipelines. The mean values of esters contents points that the analytical precision from atomic absorption measurements was not enough to support a statistically reliable interpretation of the chemical leaching of metals into the biodiesel; a more accurate set of data must be obtained with more sensitive chemical analytical techniques. From the Mössbauer data, the surface of the non - galvanized steels in contact with this biodiesel for up to 105 days tend to be somehow protected against most oxidative reactions even in direct contact with air, although few amount magnetite $\left(\mathrm{Fe}_{3} \mathrm{O}_{4}\right)$ was detected.
\end{abstract}

Keywords: biodiesel; macaúba; corrosion; carbon steel.

\section{INTRODUÇÃO}

Mitigar os efeitos do uso de energia não renovável, como o petrodiesel, significa melhorar as condições ambientais. ${ }^{1} \mathrm{Um}$ dos pontos favoráveis do ciclo do biodiesel é que o gás carbônico, vilão do efeito estufa, é consumido pelas próprias plantas oleaginosas utilizadas para sua produção, através do processo de fotossíntese. ${ }^{2} \mathrm{O}$ biocombustível é mais comumente produzido via reação de transesterificação dos triacilgliceróis de um óleo com um álcool de cadeia curta, sob condições de catálise homogênea ou heterogênea, ácida ou básica, produzindo os ésteres correspondentes e glicerina. ${ }^{3}$

A palmeira macaúba (Acrocomia aculeata (Jacq.) Lodd. ex Mart.) alcança relativamente alta produtividade em óleo. Tem sido apontada como fonte alternativa promissora para a produção industrial de biodiesel, visto que, com manejo adequado da cultura e com coleta tecnicamente correta do fruto, a produtividade da macaúba pode chegar facilmente a 6 toneladas de óleo por hectare. ${ }^{4,5}$

$\mathrm{O}$ advento do biodiesel suscitou a necessidade de se construir tanques de armazenamento e de dutos de transporte apropriados. ${ }^{6} \mathrm{O}$ aço carbono não tem muita resistência à corrosão e, comumente, os recipientes de estocagem ou escoamento, sem recobrimento protetor interno, sofrem a corrosão pela ação do oxigênio ou de diferentes contaminantes no líquido estocado. ${ }^{7}$

A corrosão metálica é a modificação química da superfície de um metal (no caso em alusão, o aço), quando da sua interação

*e-mail: jdfabris@gmail.com química ou eletroquímica, em um meio qualquer, por exposição direta ao agente corrosivo, promovendo a lixiviação de elementos químicos, com algum desprendimento de energia. ${ }^{8}$ A ocorrência de água ou ácidos graxos livres tende a potencializar o caráter corrosivo do biodiesel. ${ }^{3,4,9} \mathrm{O}$ maior grau de insaturação dos ácidos graxos, das gorduras e dos óleos, tende a aumentar a rancidez oxidativa. ${ }^{10}$ Os biodieseis produzidos a partir de óleos e gorduras com predominância de ácidos graxos insaturados, como os da soja ou do algodão, são os mais suscetíveis à oxidação pelo ar atmosférico, potencializada pela ação da umidade, luz, calor e pelo contato com cátions metálicos. ${ }^{2}$ Óleos de algumas plantas oleaginosas, como o da soja, têm propriedades químicas que promovem a oxidação do biodiesel, comprometendo o tempo de estocagem em tanques de parede de aço. ${ }^{10} \mathrm{O}$ comportamento químico do biodiesel, em relação ao diesel de petróleo, tem instigado pesquisadores a buscar por mecanismos que solucionem problemas relacionados i) ao desempenho daquele biocombustível em temperaturas baixas, ii) à qualidade do combustível e dos materiais que o contém ao longo de processos oxidativos, como a auto-oxidação que os ésteres sofrem e que abrange três estágios: a etapa de iniciação, em que há formação de radical livre que ataca o biodiesel subtraindo-lhe um átomo de hidrogênio alílico, gerando um radical; a etapa de propagação na qual o radical alílico interage com uma molécula de oxigênio, produzindo radicais peróxidos que subtraem da molécula de éster outro hidrogênio e produzem um hidroperóxido e um novo radical alílico e assim sucessivamente, de forma mais lenta; na fase denominada de etapa de término, ocorrem reações de recombinação e quebra de 
radicais formados anteriormente, transformando-os em substâncias não reativas, tais como álcoois, cetonas, éteres, alcanos, ácidos orgânicos, aldeídos e oligômeros, entre outras. Com a oxidação do biodiesel, ocorrem também mudanças em suas propriedades químicas e físicas e aumentam seu efeito corrosivo em equipamentos metálicos de partes de veículos. ${ }^{3}$

A consolidação das viabilidades técnica, econômica e ambiental do biodiesel como combustível alternativo está, em parte, atrelada a algumas particularidades químicas, sobretudo as que podem acarretar algumas dificuldades para a indústria petrolífera do país, tais como a variação do teor de ésteres, desenvolvimento de sedimentos em depósitos ou em motores e a ocorrência de compostos oxigenados, que acumulam desgaste e modificação química de tanques, tubulações ou bombas. ${ }^{10}$ Depende, também, do desenvolvimento de novas tecnologias que ampliem sua resistência à oxidação, quando acondicionados por longo tempo, em reservatórios de estocagem, diminuindo, assim, a corrosão metálica dos recipientes e os efeitos da lixiviação de elementos químicos metálicos no líquido. A aplicação de revestimentos galvânicos, com metais mais nobres que o aço, tais como o zinco, é especialmente interessante, em razão da capacidade de compor um denso e aderente filme protetor na superfície metálica, tornando a taxa de corrosão inferior à taxa observada em materiais ferruginosos. ${ }^{11}$ Diante das expectativas de aumento da produção e do uso do biodiesel obtido do óleo da amêndoa da macaúba, bem como da sua estocagem em tanques ou do escoamento desse fluido em oleodutos, são recomendadas avaliações da alteração da composição química do biodiesel estocado em reservatórios de aço carbono ou em aço carbono galvanizado.

O objetivo primordial deste trabalho foi o de avaliar a composição e o teor do biodiesel obtido da transesterificação dos triacilgliceróis do óleo de amêndoa de macaúba com metanol, além do comportamento dos ésteres metílicos produzidos, por ensaios de imersão estática de amostras de aços carbono galvanizados e não galvanizados, bem como monitorar a lixiviação dos elementos metálicos do aço no biodiesel, compostos ferruginosos formados nas superfícies dos aços e a taxa de corrosão ao final dos ensaios, por meio do cálculo da perda de massa.

\section{PARTE EXPERIMENTAL}

\section{Caracterização do óleo e do biodiesel do óleo de amêndoa da macaúba}

O óleo vegetal precursor utilizado no presente estudo foi adquirido da Cooperativa Riachão, Associação de Pequenos Trabalhadores Rurais de Riacho D'Antas, localizada em Montes Claros, MG. O óleo de amêndoa da macaúba (OAM) in natura foi extraído pelo processo de prensagem a frio e caracterizado físico-quimicamente, em triplicata, em relação ao índice de acidez (IA), índice de saponificação (IS), índice de peróxido (IP), teor de água, seguindo metodologias estabelecidas pela American Society for Testing and Materials (ASTM) e pela Association of Official Analytical Chemists (AOAC) e Instituto Adolfo Lutz. ${ }^{12-14}$

Para a produção de 10,5 L do biodiesel de OAM, utilizou-se a reação de transesterificação alcalina, com uso do hidróxido de sódio $(\mathrm{NaOH})$ como catalisador da reação, e proporção mássica em gramas do OAM:metanol 5:1. A proporção mássica do catalisador em relação ao OAM foi de 1\%; OAM:NaOH 100:1.

Todo o biodiesel do OAM produzido foi estocado em um único galão de plástico e, posteriormente, foi caracterizado segundo os mesmos parâmetros físicos-químicos usuais para o OAM, mas, também, para o índice de refração (IR), a densidade relativa (D), a viscosidade cinemática (VC) e o teor de éster metílico.
A composição em ésteres do biodiesel preparado foi obtida em cromotógrafo de fase gasosa acoplado ao espectrômetro de massas, modelo GC-MS QP2010 (Shimadzu Corporation), provido de uma coluna capilar de sílica fundida RxI-1 ms (Restek Co.).

\section{Preparo das barras de aços, caracterização química e galvanização}

As amostras dos dois tipos de aço foram gentilmente cedidas pela USIMINAS (Usinas Siderúrgicas de Minas Gerais S.A.), indústria metalúrgica situada na cidade de Ipatinga, MG. O aço carbono API 5L grau X65 (abreviadamente AC API), que é empregado no transporte de produtos petrolíferos líquidos, tem a seguinte composição química (massa\%): $\mathrm{C}=0,08 \% ; \mathrm{Si}=0,20 \% ; \mathrm{Mn}=1,50 \%$ e $\mathrm{Al}=0,030 \%$, com adição de $\mathrm{Nb}=0,045 \% ; \mathrm{V}=0,035 \%$ e $\mathrm{Ti}=0,015 \%$; o aço carbono ASTM A283 grau C (AC ASTM), que é utilizado para a produção de recipientes de armazenamento de combustível, tem a seguinte composição química (massa $\%$ ): $\mathrm{C}=0,14 \% ; \mathrm{Si}=0,20 \% ; \mathrm{Mn}=0,65 \%$ e $\mathrm{Al}=0,030 \%$.

As amostras de aço foram cortadas em barras com dimensões de $150 \mathrm{~mm} \times 10 \mathrm{~mm} \times 10 \mathrm{~mm}$. As barras assim obtidas foram furadas em uma das extremidades, com furos de 2 mm de diâmetro, para suspensão no contato direto com o biodiesel de OAM. Antes da imersão no biodiesel de OAM, as barras de aço foram previamente polidas com lixas de granulometrias 80, 180 e 400, lavadas com água deionizada e com acetona. Depois de limpas, as barras foram pesadas, para cálculo da taxa de corrosão. Para cada tipo de aço carbono foram cortadas sete barras, das quais uma foi separada como amostra controle; três correspondentes ao aço não galvanizado foram colocadas diretamente em contato com o biodiesel de OAM (ensaio em triplicata) e três foram submetidas à galvanização e posteriormente imersas em biodiesel de OAM (ensaio em triplicata).

A galvanização consistiu no tratamento de seis barras de aço, três do AC API e três do AC ASTM, respectivamente, denominadas de AG API e AG ASTM. O procedimento consistiu, inicialmente, da aplicação de um desengraxante químico, seguido da aplicação de ácido muriático, por aproximadamente $15 \mathrm{~min}$, e da imersão das amostras numa solução de cloreto de zinco e cloreto de amônio, para favorecer a aderência do zinco. Por fim, as barras foram imersas em zinco líquido a $445^{\circ} \mathrm{C}$, por $\sim 2$ min, obtendo-se cobrimento com espessura de $100 \mu \mathrm{m}$. Depois de galvanizadas, as barras foram pesadas, para cálculo da taxa de corrosão.

\section{Ensaios de imersão estática dos aços carbono e aços carbono galvanizados no biodiesel de OAM}

Os testes de imersão estática ocorreram em triplicata e consistiram na imersão de parte da amostra de $10 \mathrm{~cm}^{2}$ das barras de aço AC API, AG API, AC ASTM e AG ASTM em 700 mL de biodiesel de OAM estático, com razão volume: área de $70 \mathrm{~mL} \mathrm{~cm}^{-2}$, em frascos âmbar. A parte superior das barras, acima do fluido, foi isolada com fita de PVC. Amostras em triplicata do biodiesel de OAM sem contato com os aços mencionados, em frasco âmbar, foram usadas como controle. As 15 amostras de biodiesel foram armazenadas à temperatura ambiente (aproximadamente, $18,8^{\circ} \mathrm{C}$ ) e ao abrigo da luz, por um período de 105 dias, nos quais foram coletados volumes de 1,5 mL de amostras de biodiesel para realização de análises de teor de éster, $1,5 \mathrm{~mL}$ de amostra para cálculo do índice de acidez do biodiesel e 1,5 mL para identificação e caracterização dos metais lixiviados no biodiesel, em diferentes tempos de armazenamento: $\mathrm{t}=1 ; 2 ; 3 ; 4 ; 6 ; 13 ; 20 ; 35 ; 57$ e 105 dias, totalizando dez séries de coletas. 
Análise estatística das concentrações dos ésteres e quantificação dos metais lixiviados no biodiesel de OAM por absorção atômica (AAS)

Para a comparação das médias dos valores de concentrações em triplicatas dos ésteres de óleo de amêndoa de macaúba, em diferentes tempos de exposição e para cada teste de imersão das barras de aço, foi utilizado o teste de Scott-Knott, com nível de significância $p=0,05$. As análises foram conduzidas utilizando o software SISVAR ${ }^{\circledR}$ Versão 5.6, de acesso livre. ${ }^{15}$

Para quantificação dos elementos metálicos possivelmente lixiviados nos biodieseis, foi preparada, inicialmente: uma solução estoque de ferro $100 \mathrm{mg} \mathrm{L}^{-1}$ (Vetec), com a transferência de $5 \mathrm{~mL}$ da solução comercial de $1000 \mathrm{mg} \mathrm{L}^{-1}$ de ferro para um balão com volume de $50 \mathrm{~mL}$ e complemento do volume restante com água deionizada. A partir dessa solução, preparou-se cinco soluções padrão de calibração para o ferro, a partir de diluições de $0 ; 1,0 ; 2,5 ; 5,0$ e 7,5 mL da solução estoque de $100 \mathrm{mg} \mathrm{L}^{-1}$ para balões de $50 \mathrm{~mL}$ e completou-se o volume com água deionizada, obtendo-se as concentrações $0 ; 2,0 ; 5,0 ; 10,0$ e 15,0 mg L ${ }^{-1}$, empregadas para a construção da curva de calibração.

Esse mesmo procedimento de preparação da solução estoque foi realizado, particularmente, para o zinco e manganês, utilizando-se solução comercial $1000 \mathrm{mg} \mathrm{L}^{-1}$ (Vetec) e posterior preparo da solução estoque correspondente a cada elemento foco desse estudo. Realizaram-se diluições de $0 ; 0,1 ; 0,25 ; 0,5$ e $1,0 \mathrm{~mL}$ da solução estoque de zinco $\left(100 \mathrm{mg} \mathrm{L}^{-1}\right)$ para balões de $50 \mathrm{~mL}$, completandose o volume com água deionizada. Obtiveram-se cinco soluções padrão de calibração para o zinco com concentrações $0 ; 0,2 ; 0,5$; 1,0 e $2,0 \mathrm{mg} \mathrm{L}^{-1}$. Igualmente, diluíram-se volumes de $0 ; 0,5 ; 1,5 ; 2,5$ e $5 \mathrm{~mL}$ de solução estoque ( $\left.100 \mathrm{mg} \mathrm{L}^{-1}\right)$ de manganês em balões de $50 \mathrm{~mL}$, que posteriormente foram completados com água deionizada, obtendo-se soluções padrão de calibração com as concentrações 0 ; 1,0; 3,0; 5,0 e 10,0 $\mathrm{mg} \mathrm{L}^{-1}$. A partir dos dados das concentrações dos elementos citados construíram-se as curvas de calibração.

As medidas espectrométricas foram realizadas em um equipamento de absorção atômica com atomização em chama, marca Varian, modelo Spectrum 50B. Das concentrações dos padrões e das respectivas leituras de absorbância, gerou-se um gráfico e a equação da reta de calibração para os elementos ferro, zinco e manganês.

As amostras dos biodieseis coletadas nos diferentes tempos de exposição aos aços AC API, AG API, AC ASTM e AG ASTM foram preparadas utilizando-se $400 \mu \mathrm{L}$ de biodiesel de OAM, que, após calcinados a $550{ }^{\circ} \mathrm{C}$ em estufa, foram diluídos em $5 \mathrm{~mL}$ de solução de $\mathrm{HCl}: \mathrm{HNO}_{3}$ a $1 \%$ (v:v), para, então, serem analisados, em triplicata, por AAS. Pelas equações obtidas, foram calculados os teores dos elementos metálicos presente nas amostras, levando-se em conta as diluições realizadas.

\section{Espectroscopia Mössbauer e taxa de corrosão (TC) das barras de aço}

Para as medidas Mössbauer, utilizaram-se amostras de barras controle dos aços AC API e AC ASTM, sem imersão no biodiesel de OAM, além de barras dos aços AC API, AC ASTM, AG API e AG ASTM após imersão em biodiesel de OAM. As camadas superficiais das barras de aço foram removidas com uma microrretífica da Black \& Decker RT650 equipada com uma ponta montada de carbureto de silício. Os pós assim obtidos foram submetidos a medidas experimentais por espectroscopia Mössbauer do ${ }^{57} \mathrm{Fe}$ em geometria de transmissão de raios $\gamma$. Os espectros das amostras na temperatura ambiente e a $80 \mathrm{~K}$ foram obtidos em um espectrômetro convencional com aceleração constante de uma fonte de ${ }^{57} \mathrm{Co}$ em matriz de Rh e $\sim 50 \mathrm{mCi}$ de atividade. Os deslocamentos isoméricos foram corrigidos em relação ao $\alpha \mathrm{Fe}$ na temperatura ambiente, padrão também usado para a calibração da escala de velocidade Doppler. Os dados coletados foram ajustados por um algoritmo pelo método dos mínimos quadrados, utilizando o programa de computador WinNormos ${ }^{\mathrm{TM}}$ for Igor ${ }^{\mathrm{TM}}$ Pro 6.1.

As massas das barras de aço AC API, AG API, AC ASTM e AG ASTM foram registradas antes e após a imersão no biodiesel de OAM e, conforme norma ASTM G1-03, foram submetidas à decapagem ácida por $10 \mathrm{~s}$, lavadas com álcool isopropílico e acetona, para retirada de produtos de corrosão. As barras de aço após a secagem foram pesadas para averiguação da diferença da massa (perda de massa) e cálculo da taxa de corrosão (TC), de acordo com a Equação 1 e classificação conforme os níveis de corrosividade dos aços carbono.

$$
\mathrm{TC}=\frac{\mathrm{K} \times \mathrm{W}}{\mathrm{A} \times \mathrm{T} \times \mathrm{D}}
$$

onde: $\mathrm{K}=8.76 \times 10^{4} \mathrm{~mm}^{\mathrm{ano}}{ }^{-1}$, é uma constante; $\mathrm{T}=$ tempo de exposição, em horas; $\mathrm{A}=$ área da peça metálica $\mathrm{em} \mathrm{cm}^{2} ; \mathrm{W}=$ perda de massa, em gramas (peso inicial - peso final); $\mathrm{D} \approx 7,86 \mathrm{~g} \mathrm{~cm}^{-3}(\mathrm{Fe})$ densidade dos aços não galvanizados e $\mathrm{D} \approx 7,14 \mathrm{~g} \mathrm{~cm}^{-3}(\mathrm{Zn})$ é a densidade dos aços galvanizados.

Utilizou-se a densidade do zinco para a avaliação das TC dos aços carbono galvanizados; a classificação dos valores encontrados foi feita de acordo com a norma NACE RP $0775^{16}$ para todas as amostras de aço utilizadas neste trabalho.

\section{RESULTADOS E DISCUSSÃO}

\section{Caracterização físico-química do OAM e do biodiesel obtido}

Os resultados obtidos da caracterização do óleo de amêndoa da macaúba e do biodiesel produzido pela transesterificação dos triacilgliceróis do óleo estão apresentados na Tabela 1.

Tabela 1. Resultados dos testes de caracterização do OAM e do biodiesel

\begin{tabular}{lccc}
\hline Parâmetro analítico & OAM & Biodiesel & Referência ANP \\
\hline Índice de acidez/mg KOH g-1 & $4,05(1)$ & $0,25(1)$ & Máx. 0,5 \\
$\begin{array}{l}\text { Índice de peróxido/ } \\
\text { meq } 1000 \mathrm{~g} \mathrm{~g}^{-1}\end{array}$ & $34(2)$ & $36(2)$ & $\mathrm{NC}$ \\
$\begin{array}{l}\text { Índice de saponificação/ } \\
\text { mg KOH g- }\end{array}$ & $193(1)$ & $192(1)$ & $\mathrm{NC}$ \\
$\begin{array}{l}\text { Densidade relativa a } 20{ }^{\circ} \mathrm{C} \\
\text { Massa específica a } 20{ }^{\circ} \mathrm{C} /\end{array}$ & - & $0,871(1)$ & 0,850 a 0,900 \\
$\mathrm{~kg} \mathrm{~m}^{-3}$ & - & $871(1)$ & 850 a 900 \\
$\begin{array}{l}\text { Viscosidade a } 40{ }^{\circ} \mathrm{C} / \mathrm{mm}^{2} \mathrm{~s}^{-1} \\
\text { Índice de refração }\end{array}$ & - & $4,8(1)$ & 3,0 a 6,0 \\
Teor de água/mg kg ${ }^{-1}$ & $1176(30)$ & $890(9)$ & Máx. 200 \\
Teor de éster/massa\% & - & $94,34(2)$ & Min. 96,5 \\
\hline
\end{tabular}

Valores expressos como média (desvio-padrão) de amostras analisadas em triplicata. $\mathrm{NC}=$ Não cita.

O cálculo do IA é fundamental para o controle de qualidade da matéria-prima que será utilizada para a síntese de biodiesel. Para o OAM, IA = 4,05(1) $\mathrm{mg} \mathrm{KOH} \mathrm{g}^{-1}$, correspondente a um óleo de baixo teor de acidez e, portanto, adequado para catálise básica homogênea. $\mathrm{O}$ valor do IA obtido na caracterização do biodiesel de OAM foi de $0,25(1) \mathrm{mg} \mathrm{KOH} \mathrm{g}^{-1}$ o que indica que houve uma eficiência da reação de transesterificação via catálise básica para a síntese dos ésteres metílicos. ${ }^{17-19}$ 
O IP obtido para o OAM foi de 34(2) meq $1000 \mathrm{~g}^{-1}$. A Resolução RDC n $270,{ }^{20}$ de 22 de setembro de 2005, prevê que o IP para óleos prensados a frio e não refinados, para consumo humano, deve ser no máximo até 15 meq $\mathrm{kg}^{-1}$. Observa-se boa concordância dos valores encontrados para o índice de peróxido do biodiesel de OAM com o reportado na literatura científica. Valores superiores a 300 meq $1000 \mathrm{~g}^{-1}$ são considerados altos para biodiesel e indicam alguma degradação do biocombustível. ${ }^{10} \mathrm{O}$ IP encontrado neste trabalho para o biodiesel de OAM foi de 36(2) meq $1000 \mathrm{~g}^{-1}$.

O IS indica a quantidade de álcali necessária para neutralizar os ácidos graxos livres presentes em um grama de amostra, que depende do nível de degradação e da estabilidade dos óleos vegetais ou das gorduras. Neste trabalho, o IS encontrado para o biodiesel de OAM foi de 192(1) $\mathrm{mg} \mathrm{KOH} \mathrm{g}^{-1}$, valor bem próximo ao da matéria-prima utilizada para a síntese de biodiesel, IS = 193(1) $\mathrm{mg} \mathrm{KOH} \mathrm{g}^{-1}$, o que demonstra a baixa proporção de ácidos graxos de baixo peso molecular. ${ }^{19} \mathrm{~A}$ maioria dos ácidos graxos presentes no biodiesel adulterado é de cadeia curta, de menor peso molecular. ${ }^{17-19}$

A densidade relativa e a massa específica do biodiesel de OAM a $20{ }^{\circ} \mathrm{C}$ foram, respectivamente, $0,871(1)$ e $871 \mathrm{~kg} \mathrm{~m}^{-3}$, dentro dos limites recomendados pela ANP. ${ }^{17}$

O valor obtido para a viscosidade do biodiesel metílico de OAM foi de $4,8(1) \mathrm{mm}^{2} \mathrm{~s}^{-1}$, estando dentro dos limites estabelecidos pela ANP. ${ }^{17} \mathrm{~A}$ fim de proporcionar um melhor desempenho dos motores, a viscosidade cinemática de misturas de biodiesel-diesel deve ser relativamente baixa, na medida em que qualquer viscosidade maior seria responsável por um maior consumo de energia na bomba de combustível e pelo mau desempenho em pulverização, atomização e aumento do consumo de combustível. ${ }^{21}$

O índice de refração para o biodiesel de OAM é 1,451(1), próximo ao valor reportado na literatura científica, para biodiesel, que é de $\mathrm{n}=1,476$, e próximo aos limites recomendados para óleos, de 1,466 a 1,470 .

O teor de água encontrado para o OAM foi de 1176(30) $\mathrm{mg} \mathrm{kg}^{-1}$ equivalente a $0,1176 \%\left(0,1176 / 100 \mathrm{mg} \mathrm{mg}^{-1}\right)$ de umidade, o que mostra que as condições do óleo eram apropriadas para a reação de transesterificação via catálise alcalina, em que são recomendadas condições de umidade abaixo de $1 \% \cdot{ }^{20} \mathrm{O}$ teor de água encontrado para o biodiesel de OAM foi de 890(9) $\mathrm{mg} \mathrm{kg}^{-1}$, valor em desacordo com o máximo recomendado pela ANP. O estudo da influência da água residual e da incidência de radiação UV nos processos oxidativos do biodiesel de óleos de canola, soja, linhaça e microalgas, por meio do período de indução, mostra que a proporção de água no biodiesel entre aproximadamente 190 ppm e 850 ppm não alterou significativamente o período de indução para os biodieseis que não estavam expostos à radiação UV, em um nível de confiança de $95 \%$ (teste pareado de Student). ${ }^{22}$ Leung et al. ${ }^{23}$ mostraram que a água no biodiesel não modifica os valores de índice de acidez nem de pureza, em termos de ésteres; a exposição ao ar e alta temperatura são os principais fatores que comprometem a taxa de degradação. Sendo assim, procedeu-se os testes de imersão com o biodiesel aqui obtido.

O rendimento químico da reação de transesterificação, medido pelo teor de éster encontrado no biodiesel sintetizado, foi 94,34(2) massa\%, abaixo, mas muito próximo, do valor mínimo recomendado pela ANP. O óleo da amêndoa da macaúba é rico em ácido láurico. Observa-se, pois, a dominância do laurato de metila (C12:0) na composição do biodiesel.

\section{Ensaios de corrosão por imersão estática entre o biodiesel de OAM e aços carbono}

Para simular as condições de armazenamento, foram estabelecidos ensaios de imersão estática dos aços AC API, AG API, AC ASTM e
AG ASTM no biodiesel de OAM. Realizaram-se análises das concentrações dos ésteres, do índice de acidez e dos metais lixiviados dos aços para o biodiesel e, para facilitar a avaliação dos dados obtidos, tratamentos estatísticos foram aplicados para as concentrações dos ésteres.

\section{Análise das concentrações médias de cada éster do biodiesel de OAM em relação ao aço e ao tempo de armazenamento}

O teste de comparações múltiplas de médias escolhido foi o método de Scott-Knott, que é baseado na análise de variância por agrupamento univariado, por separação das médias em grupos homogêneos, com diferenças mínimas significativas entre elas. $\mathrm{O}$ método difere de outros procedimentos mais comuns por não apresentar ambiguidades na comparação de duas médias que, embora tidas como diferentes entre si, diferem de uma terceira. ${ }^{24}$

Os teores médios do éster C8:0, em relação ao tempo de estocagem, variaram para os biodieseis em contato com os aços AC API, AG API e AG ASTM, o que nos permitiu classificá-los em dois grupos distintos de concentrações médias (a1 e a2): as médias do grupo a2 são maiores que as médias do grupo a1, pelo teste de Skott-Knott $5 \%$. Isso indica que as concentrações do éster aumentaram em relação ao tempo de armazenamento para os ensaios de imersão estática dos biodieseis com o AC API (aos 57 dias), AG API (a partir dos 35 dias) e AG ASTM (a partir dos 20 dias), mostrando sinais de degradação aos 105 dias de armazenamento.

A ocorrência de íons metálicos no biodiesel pode causar degradação dos ésteres. No entanto, a extensão da deterioração depende do potencial de oxidação dos íons metálicos e das condições prevalecentes, como a temperatura e o teor de água no combustível. ${ }^{1}$ As concentrações médias do C8:0 do biodiesel em contato com o AC ASTM e do biodiesel puro não diferiram estatisticamente pelo teste de Scott-Knott (5\%). Logo, apenas o biodiesel em contato com o AC ASTM teve comportamento parecido com o biodiesel controle.

Em relação ao período de armazenagem, o biodiesel de OAM controle não apresentou alterações significativas em suas concentrações pelo teste de Scott-Knott a 5\% para o éster do ácido graxo C10:0. Os biodieseis com ensaios de imersão estática com os aços AC API, AG API, AC ASTM e AG ASTM tiveram suas concentrações de C10:0 distribuídas em grupos distintos (a1, a2 e a3) indicando aumento (aos 57, 35, 13 e 20 dias, respectivamente) e diminuição de suas concentrações durante o armazenamento, exceto o biodiesel em contato com AC ASTM.

O éster do ácido graxo C12:0 constitui 34,70\% de todos os ésteres que compõem o biodiesel de OAM, em relação ao período de armazenamento. Todos os biodieseis, inclusive o controle, tiveram pelo menos dois grupos de médias distintas pelo teste de Scott-Knott (5\%). O biodiesel controle e os biodieseis com imersão dos aços AC ASTM e AG ASTM tiveram comportamentos semelhantes (suas concentrações aumentaram a partir de 20, 13 e 20 dias, respectivamente; Tabela 2). Os biodieseis em contato com os aços AC API e AG API, tiveram suas concentrações de C12:0 aumentadas aos 57 e a partir dos 35 dias, respectivamente, mas revelaram sinais de degradação química aos 105 dias de armazenamento.

Em relação ao éster C14:0, os ensaios do biodiesel de OAM com os aços AC ASTM e AG ASTM tiveram comportamento semelhante ao biodiesel controle, durante todo o tempo do experimento, apenas aumentando suas concentrações e não sofrendo degradação química (Tabela 3). Os ensaios que apresentaram degradação química do éster C14:0 aos 105 dias de armazenagem foram os biodieseis com ensaios de imersão dos aços AC API e AG API.

Durante o armazenamento, o éster C16:0 do biodiesel controle e do biodiesel em ensaio de corrosão com o aço AC ASTM apresentou comportamento semelhante em suas concentrações, sem degradar-se, 
Tabela 2. Concentrações médias do éster C12:0, em mg mL${ }^{-1}$, do biodiesel puro e em contato com os aços ao longo dos períodos de imersão

\begin{tabular}{|c|c|c|c|c|c|}
\hline \multirow{2}{*}{ Tempo (dias) } & \multicolumn{5}{|c|}{ Concentração média do éster C12:0/mg mL $\mathrm{m}^{-1}$} \\
\hline & Bodiesel puro & Biodiesel + AC API & Biodiesel + AG API & Biodiesel + AC ASTM & Biodiesel + AG ASTM \\
\hline 1 & $3,43(8)^{\mathrm{a} 1}$ & $3,61(7)^{\mathrm{a} 1}$ & $3,09(9)^{\mathrm{a} 1}$ & $3,27(9)^{\mathrm{a} 1}$ & $3,3(5)^{\mathrm{a} 1}$ \\
\hline 2 & $3,13(5)^{\mathrm{a} 1}$ & $3,61(4)^{\mathrm{a} 1}$ & $3,0(2)^{\mathrm{a} 1}$ & $3,22(3)^{\mathrm{a} 1}$ & $3,3(3)^{\mathrm{a} 1}$ \\
\hline 3 & $3,48(9)^{\mathrm{a} 1}$ & $3,6(1)^{\mathrm{a} 1}$ & $3,1(2)^{\mathrm{a} 1}$ & $3,41(5)^{\mathrm{a} 1}$ & $3,0(2)^{\mathrm{a} 1}$ \\
\hline 4 & $3,37(3)^{\mathrm{a} 1}$ & $3,57(4)^{\mathrm{a} 1}$ & $3,1(2)^{\mathrm{al}}$ & $3,3(2)^{a 1}$ & $3,0(2)^{a 1}$ \\
\hline 6 & $3,3(1)^{\mathrm{a} 1}$ & $3,62(6)^{\mathrm{a} 1}$ & $3,2(1)^{\mathrm{a} 1}$ & $3,3(2)^{\mathrm{a} 1}$ & $3,2(2)^{\mathrm{al}}$ \\
\hline 13 & $3,4(3)^{\mathrm{a} 1}$ & $3,4(3)^{\mathrm{a} 1}$ & $3,5(2)^{\mathrm{a} 1}$ & $4,1(3)^{\mathrm{a} 2}$ & $3,5(2)^{\mathrm{a} 1}$ \\
\hline 20 & $3,7(3)^{\mathrm{a} 2}$ & $3,6(5)^{\mathrm{al}}$ & $3,7(3)^{\mathrm{a} 1}$ & $3,8(4)^{\mathrm{a} 2}$ & $4,2(6)^{\mathrm{a} 2}$ \\
\hline 35 & $3,8(3)^{\mathrm{a} 2}$ & $3,9(2)^{\mathrm{al}}$ & $4,1(4)^{\mathrm{a} 2}$ & $4,0(2)^{\mathrm{a} 2}$ & $4,4(5)^{\mathrm{a} 2}$ \\
\hline 57 & $4,0(8)^{a^{2}}$ & $5,3(3)^{\mathrm{a} 2}$ & $4,7(5)^{\mathrm{a} 2}$ & $4,0(7)^{\mathrm{a} 2}$ & $4,3(4)^{\mathrm{a} 2}$ \\
\hline 105 & $4,3(2)^{\mathrm{a} 2}$ & $4,0(7)^{\mathrm{a} 1}$ & $3,4(3)^{a 1}$ & $3,9(3)^{\mathrm{a} 2}$ & $4,2(2)^{\mathrm{a} 2}$ \\
\hline
\end{tabular}

Valores expressos como média (desvio-padrão) de amostras analisadas em triplicata. Médias seguidas de mesma letra minúscula e número na coluna não diferem estatisticamente entre si pelo teste de Scott e Knott a (5\%).

Tabela 3. Concentrações médias do éster C14:0, em mg mL $\mathrm{m}^{-1}$, do biodiesel puro e em contato com os aços ao longo dos períodos de armazenamento

\begin{tabular}{|c|c|c|c|c|c|}
\hline \multirow{2}{*}{ Tempo (dias) } & \multicolumn{5}{|c|}{ Concentração média do éster C14:0/mg mL $\mathrm{mL}^{-1}$} \\
\hline & Biodiesel puro & Biodiesel + AC API & Biodiesel + AG API & Biodiesel + AC ASTM & Biodiesel + AG ASTM \\
\hline 1 & $0,93(1)^{\mathrm{a} 1}$ & $0,99(2)^{\mathrm{a} 1}$ & $0,84(3)^{\mathrm{a} 1}$ & $0,90(3)^{\mathrm{a} 1}$ & $0,9(1)^{\mathrm{a} 1}$ \\
\hline 2 & $0,8(1)^{\mathrm{a} 1}$ & $0,99(1)^{\mathrm{a} 1}$ & $0,82(7)^{\mathrm{a} 1}$ & $0,88(1)^{\mathrm{a} 1}$ & $0,90(9)^{\mathrm{a} 1}$ \\
\hline 3 & $0,94(2)^{\mathrm{a} 1}$ & $0,98(2)^{\mathrm{a} 1}$ & $0,81(1)^{\mathrm{a} 1}$ & $0,92(1)^{\mathrm{a} 1}$ & $0,80(6)^{\mathrm{a} 1}$ \\
\hline 4 & $0,91(2)^{\mathrm{a} 1}$ & $0,97(3)^{\mathrm{a} 1}$ & $0,84(5)^{\mathrm{a} 1}$ & $0,90(4)^{\mathrm{a} 1}$ & $0,82(7)^{\mathrm{a} 1}$ \\
\hline 6 & $0,90(3)^{\mathrm{a} 1}$ & $0,99(2)^{\mathrm{a} 1}$ & $0,88(3)^{\mathrm{a} 1}$ & $0,92(6)^{\mathrm{a} 1}$ & $0,86(5)^{\mathrm{a} 1}$ \\
\hline 13 & $0,96(9)^{\mathrm{a} 1}$ & $0,9(1)^{\mathrm{a} 1}$ & $0,93(6)^{\mathrm{a} 1}$ & $1,15(7)^{\mathrm{a} 2}$ & $1,00(5)^{\mathrm{a} 2}$ \\
\hline 20 & $1,03(8)^{\mathrm{a} 2}$ & $1,0(1)^{\mathrm{a} 1}$ & $1,0(1)^{\mathrm{a} 2}$ & $1,1(1)^{\mathrm{a} 2}$ & $1,1(2)^{a 2}$ \\
\hline 35 & $1,02(7)^{\mathrm{a} 2}$ & $1,09(7)^{\mathrm{a} 1}$ & $1,1(1)^{\mathrm{a} 2}$ & $1,07(4)^{\mathrm{a} 2}$ & $1,2(2)^{\mathrm{a} 2}$ \\
\hline 57 & $1,1(2)^{\mathrm{a}^{2}}$ & $1,4(1)^{\mathrm{a}^{2}}$ & $1,2(1)^{a 3}$ & $1,1(2)^{\mathrm{a}^{2}}$ & $1,1(1)^{\mathrm{a} 2}$ \\
\hline 105 & $1,12(6)^{\mathrm{a} 2}$ & $1,1(2)^{a 1}$ & $0,91(9)^{\mathrm{a} 1}$ & $1,03(9)^{\mathrm{a} 2}$ & $1,09(7)^{\mathrm{a} 2}$ \\
\hline
\end{tabular}

Valores expressos como média (desvio-padrão) de amostras analisadas em triplicata. Médias seguidas de mesma letra minúscula e número na coluna não diferem estatisticamente entre si pelo teste de Scott e Knott a (5\%).

ao longo dos 105 dias do experimento (Tabela 4). Os biodieseis em contato com os aços AC API, AG API e AG ASTM apresentaram aumento das concentrações de C16:0 com o tempo de armazenamento do biocombustível, contudo os aços AC API e AG API mostraram sinais de degradação química aos 105 dias de contato, conforme verificado pelo teste de Scott e Knott.

O éster C18:0, para todos os testes realizados, foi o de comportamento mais semelhante ao biodiesel controle, durante o tempo de armazenamento. Pelo teste de Scott e Knott, houve formação de dois grupos distintos de médias apenas para as concentrações do biodiesel com imersão do AG API. Porém, esse valor parece suspeito por estar completamente fora da tendência de todas as amostras analisadas. O éster C18:0 do biodiesel controle e dos biodieseis em ensaios de corrosão não sofreu degradação, ao longo do tempo do experimento.

Em relação ao éster C18:1, observa-se que a composição manteve-se para o biodiesel puro, ao longo do experimento, não havendo diferença estatística entre as concentrações médias, pelo teste de Scott-Knott a 5\%. Os biodieseis com imersão do AC ASTM e AG ASTM apenas aumentaram suas concentrações a partir de 13 e 20 dias, respectivamante (Tabela 5). Os biodieseis de OAM com imersão do AC API e AG API tiveram degradação do éster C18:1, aos 105 dias dos experimentos. Em relação ao biodiesel em contato com o AG API, observa-se que o valor da concentração de C18:1 aos 105 dias ficou completamente fora da tendência, o que poderia ter sido causado por algum erro durante a coleta das replicatas ou manuseio inadequado das amostras para quantificação por croamtografia de fase gasosa - espectrometria de massa.
As concentrações médias do éster C18:2 tratadas pelo teste de Scott e Knott ficaram virtualmente constantes para o biodiesel controle e para o biodiesel em contato com o AG ASTM, com alguma diminuição de sua proporção média aos 13 dias de contato (Tabela 6). Os biodieseis com imersão dos aços AC API e AG API tiveram as concentrações médias de C18:2 diminuídas, aos 105 dias de experimento.

Dos dados das tabelas, os biodieseis que tiveram comportamento semelhante ao biodiesel controle e não sofreram degradação ao longo da armazenagem foram os que estavam em contato com os aços AC ASTM e AG ASTM (à exceção dos ésteres C8:0 e C10:0). Todos os ésteres dos biodieseis em ensaios de corrosão com os aços AC API e AG API sofreram degradação, aos 105 dias de imersão. Estes resultados supõem que o AC ASTM e AG ASTM garantem maior estabilidade ao biodiesel de OAM, em relação a alterações de sua composição.

\section{Índice de acidez do biodiesel de OAM após imersão das barras de aço}

Ao longo do período de armazenamento do biodiesel do óleo de amêndoa da macaúba em contato com os diferentes tipos de aço investigados, o índice de acidez foi medido com o intuito de analisar possíveis alterações do mesmo. O índice de acidez está arrolado a corrosão de partes do motor e a oxidação em tanques de armazenamento. Analisando-se a Figura 1 é possível perceber que a acidez das amostras do biodiesel controle e dos biodieseis em contato com os aços AC API, AG API, AC ASTM e AG ASTM tendeu a aumentar 
Tabela 4. Concentrações médias do éster C16:0, em mg mL ${ }^{-1}$, do biodiesel puro e em contato com os aços ao longo dos períodos de armazenamento

\begin{tabular}{clllll}
\hline \multirow{2}{*}{ Tempo (dias) } & \multicolumn{5}{c}{ Concentração média do éster metílico do ácido graxo C16:0/mg mL ${ }^{-1}$} \\
\cline { 2 - 6 } & Biodiesel puro & Biodiesel + AC API & Biodiesel + AG API & Biodiesel + AC ASTM & Biodiesel + AG ASTM \\
\hline 1 & $0,76(1)^{\mathrm{a} 1}$ & $0,82(2)^{\mathrm{a} 1}$ & $0,70(3)^{\mathrm{a} 1}$ & $0,73(4)^{\mathrm{a} 1}$ & $0,72(8)^{\mathrm{a} 1}$ \\
2 & $0,7(1)^{\mathrm{a} 1}$ & $0,82(1)^{\mathrm{a} 1}$ & $0,68(5)^{\mathrm{a} 1}$ & $0,72(1)^{\mathrm{a} 1}$ & $0,72(9)^{\mathrm{a} 1}$ \\
3 & $0,76(2)^{\mathrm{a} 1}$ & $0,81(3)^{\mathrm{a} 1}$ & $0,67(4)^{\mathrm{a} 1}$ & $0,75(1)^{\mathrm{a} 1}$ & $0,68(6)^{\mathrm{a} 1}$ \\
4 & $0,74(2)^{\mathrm{a} 1}$ & $0,80(3)^{\mathrm{a} 1}$ & $0,70(4)^{\mathrm{a} 1}$ & $0,75(1)^{\mathrm{a} 1}$ & $0,67(6)^{\mathrm{a} 1}$ \\
6 & $0,74(2)^{\mathrm{a} 1}$ & $0,82(1)^{\mathrm{a} 1}$ & $0,73(3)^{\mathrm{a} 1}$ & $0,76(3)^{\mathrm{a} 1}$ & $0,70(5)^{\mathrm{a} 1}$ \\
13 & $0,74(6)^{\mathrm{a} 1}$ & $0,72(7)^{\mathrm{a} 1}$ & $0,73(4)^{\mathrm{a} 1}$ & $0,89(4)^{\mathrm{a} 1}$ & $0,78(4)^{\mathrm{a} 1}$ \\
20 & $0,80(6)^{\mathrm{a} 1}$ & $0,8(1)^{\mathrm{a} 1}$ & $0,8(1)^{\mathrm{a} 2}$ & $0,82(8)^{\mathrm{a} 1}$ & $0,8(1)^{\mathrm{a} 2}$ \\
35 & $0,77(6)^{\mathrm{a} 1}$ & $0,81(4)^{\mathrm{a} 1}$ & $0,85(7)^{\mathrm{a} 2}$ & $0,81(6)^{\mathrm{a} 1}$ & $0,9(1)^{\mathrm{a} 2}$ \\
57 & $0,8(2)^{\mathrm{a} 1}$ & $1,03(9)^{\mathrm{a} 2}$ & $0,9(1)^{\mathrm{a} 2}$ & $0,8(1)^{\mathrm{a} 1}$ & $0,86(8)^{\mathrm{a} 2}$ \\
105 & $0,87(3)^{\mathrm{a} 1}$ & $0,8(1)^{\mathrm{a} 1}$ & $0,76(9)^{\mathrm{a} 1}$ & $0,84(6)^{\mathrm{a} 1}$ & $0,87(4)^{\mathrm{a} 2}$ \\
\hline
\end{tabular}

Valores expressos como média (desvio-padrão) de amostras analisadas em triplicata. Médias seguidas de mesma letra minúscula e número na coluna não diferem estatisticamente entre si pelo teste de Scott e Knott a (5\%).

Tabela 5. Concentrações médias do éster C18:1, em mg mL ${ }^{-1}$, do biodiesel puro e em contato com os aços ao longo dos períodos de armazenagem

\begin{tabular}{|c|c|c|c|c|c|}
\hline \multirow{2}{*}{ Tempo (dias) } & \multicolumn{5}{|c|}{ Concentração média do éster C18:1/mg mL $\mathrm{mL}^{-1}$} \\
\hline & Biodiesel puro & Biodiesel + AC API & biodiesel + AG API & Biodiesel + AC ASTM & Biodiesel + AG ASTM \\
\hline 1 & $2,37(4)^{\mathrm{a} 1}$ & $2,58(6)^{a 1}$ & $2,2(1)^{\mathrm{a} 2}$ & $2,2(1)^{\mathrm{a} 1}$ & $2,3(2)^{\mathrm{a} 1}$ \\
\hline 2 & $2,2(4)^{\mathrm{a} 1}$ & $2,61(5)^{\mathrm{a} 1}$ & $2,1(2)^{\mathrm{a}^{2}}$ & $2,23(2)^{\mathrm{a} 1}$ & $2,2(4)^{\mathrm{a} 1}$ \\
\hline 3 & $2,40(4)^{\mathrm{a} 1}$ & $2,57(7)^{\mathrm{a} 1}$ & $2,08(6)^{\mathrm{a} 2}$ & $2,3(1)^{\mathrm{a} 1}$ & $2,2(2)^{\mathrm{a} 1}$ \\
\hline 4 & $2,32(7)^{\mathrm{a} 1}$ & $2,5(1)^{\mathrm{a} 1}$ & $2,2(1)^{\mathrm{a} 2}$ & $2,3(1)^{\mathrm{a} 1}$ & $2,1(2)^{\mathrm{a} 1}$ \\
\hline 6 & $2,33(8)^{\mathrm{a} 1}$ & $2,61(4)^{\mathrm{a} 1}$ & $2,24(8)^{a 2}$ & $2,30(9)^{\mathrm{a} 1}$ & $2,2(2)^{\mathrm{a} 1}$ \\
\hline 13 & $2,3(1)^{\mathrm{a} 1}$ & $2,3(2)^{\mathrm{a} 1}$ & $2,3(1)^{\mathrm{a} 2}$ & $2,8(1)^{\mathrm{a} 2}$ & $2,4(2)^{\mathrm{a} 1}$ \\
\hline 20 & $2,5(2)^{\mathrm{a} 1}$ & $2,5(4)^{\mathrm{a} 1}$ & $2,5(3)^{\mathrm{a} 2}$ & $2,6(3)^{\mathrm{a} 2}$ & $2,6(3)^{\mathrm{a} 2}$ \\
\hline 35 & $2,4(2)^{\mathrm{a} 1}$ & $2,6(1)^{\mathrm{a} 1}$ & $2,7(2)^{\mathrm{a} 3}$ & $2,6(2)^{\mathrm{a} 2}$ & $2,9(3)^{\mathrm{a} 2}$ \\
\hline 57 & $2,7(5)^{\mathrm{a} 1}$ & $3,4(3)^{\mathrm{a} 2}$ & $3,1(3)^{\mathrm{a3}}$ & $2,6(5)^{\mathrm{a} 2}$ & $2,8(3)^{\mathrm{a} 2}$ \\
\hline 105 & $2,8(1)^{\mathrm{a} 1}$ & $2,7(5)^{\mathrm{a} 1}$ & $1(1)^{\mathrm{a} 1}$ & $2,8(2)^{\mathrm{a} 2}$ & $2,8(1)^{\mathrm{a} 2}$ \\
\hline
\end{tabular}

Valores expressos como média (desvio-padrão) de amostras analisadas em triplicata. Médias seguidas de mesma letra minúscula e número na coluna não diferem estatisticamente entre si pelo teste de Scott e Knott a (5\%).

Tabela 6. Concentrações médias do éster C18:2, em mg mL-1, do biodiesel puro e em contato com os aços ao longo dos períodos de armazenamento

\begin{tabular}{|c|c|c|c|c|c|}
\hline \multirow{2}{*}{ Tempo (dias) } & \multicolumn{5}{|c|}{ Concentração média do éster C18:2/mg mL ${ }^{-1}$} \\
\hline & Biodiesel puro & Biodiesel + AC API & Biodiesel + AG API & Biodiesel + AC ASTM & Biodiesel + AG ASTM \\
\hline 1 & $0,309(5)^{\mathrm{a} 2}$ & $0,34(1)^{\mathrm{a} 1}$ & $0,29(2)^{\mathrm{a} 1}$ & $0,29(1)^{\mathrm{a} 1}$ & $0,30(3)^{\mathrm{a} 1}$ \\
\hline 2 & $0,29(5)^{\mathrm{a} 2}$ & $0,34(1)^{\mathrm{a} 1}$ & $0,28(2)^{\mathrm{a} 1}$ & $0,292(2)^{\mathrm{a} 1}$ & $0,28(4)^{\mathrm{a} 1}$ \\
\hline 3 & $0,311(3)^{\mathrm{a} 2}$ & $0,33(1)^{\mathrm{a} 1}$ & $0,27(1)^{\mathrm{a} 1}$ & $0,30(1)^{\mathrm{a} 1}$ & $0,265(4)^{\mathrm{a} 1}$ \\
\hline 4 & $0,30(1)^{\mathrm{a} 2}$ & $0,33(1)^{\mathrm{a} 1}$ & $0,28(1)^{\mathrm{a} 1}$ & $0,30(1)^{\mathrm{a} 1}$ & $0,27(2)^{\mathrm{a} 1}$ \\
\hline 6 & $0,30(2)^{\mathrm{a} 2}$ & $0,34(6)^{\mathrm{a} 1}$ & $0,30(2)^{\mathrm{a} 1}$ & $0,30(2)^{\mathrm{a} 1}$ & $0,28(2)^{\mathrm{a} 1}$ \\
\hline 13 & $0,25(2)^{\mathrm{a} 1}$ & $0,30(6)^{\mathrm{a} 1}$ & $0,30(2)^{\mathrm{a} 1}$ & $0,37(2)^{\mathrm{a} 2}$ & $0,33(2)^{\mathrm{a} 2}$ \\
\hline 20 & $0,34(2)^{\mathrm{a} 2}$ & $0,33(5)^{\mathrm{a} 1}$ & $0,32(3)^{\mathrm{a} 1}$ & $0,34(3)^{\mathrm{a} 2}$ & $0,34(4)^{\mathrm{a} 2}$ \\
\hline 35 & $0,32(2)^{\mathrm{a} 2}$ & $0,33(1)^{\mathrm{a} 1}$ & $0,35(3)^{\mathrm{a} 2}$ & $0,32(2)^{\mathrm{a} 2}$ & $0,36(4)^{\mathrm{a} 2}$ \\
\hline 57 & $0,34(6)^{\mathrm{a} 2}$ & $0,42(4)^{\mathrm{a} 2}$ & $0,38(4)^{\mathrm{a} 2}$ & $0,32(5)^{\mathrm{a} 1}$ & $0,35(3)^{\mathrm{a} 2}$ \\
\hline 105 & $0,33(2)^{\mathrm{a} 2}$ & $0,32(5)^{\mathrm{a} 1}$ & $0,31(4)^{\mathrm{a} 1}$ & $0,34(2)^{\mathrm{a} 2}$ & $0,34(2)^{\mathrm{a} 2}$ \\
\hline
\end{tabular}

Valores expressos como média (desvio-padrão) de amostras analisadas em triplicata. Médias seguidas de mesma letra minúscula e número na coluna não diferem estatisticamente entre si pelo teste de Scott e Knott a (5\%).

contínua e discretamente até o último dia do monitoramento. Todavia, aos 57 dias do armazenamento as amostras do biodiesel em contato com os aços AG API e AC ASTM apresentaram um índice de acidez consideravelmente mais elevado, em relação às demais. Aos 105 dias do experimento, em relação ao índice de acidez do biodiesel controle, todos os biodieseis em ensaios de imersão estática com os aços tiveram aumento da acidez, destacando-se o biodiesel em contato com o AG API e com o AC ASTM. Todavia, os valores de índice de acidez obtidos no decorrer do experimento, para todos os biodieseis, ficaram dentro dos parâmetros de controle de qualidade recomendados pela ANP. ${ }^{17}$ Embora o biodiesel em contato como o AG ASTM tenha tido o valor do índice de acidez aumentado no $4^{\circ}$ dia da armazenagem, deduz-se que o mesmo tenha tido comportamento semelhante à acidez do biodiesel controle.

\section{Elementos metálicos lixiviados do aço para o biodiesel}

As amostras coletadas nos diferentes tempos de exposição foram analisadas, em triplicatas, por espectrometria de absorção atômica com atomização em chama (AAS), para quantificação de elementos 


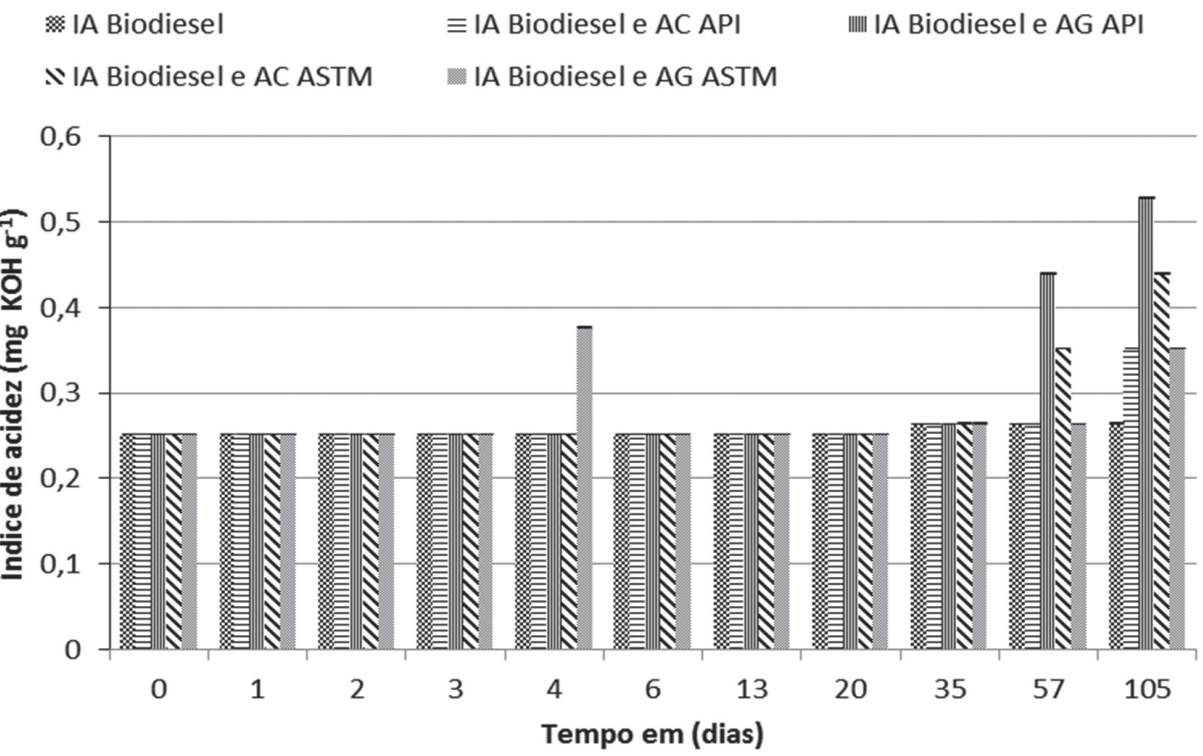

Figura 1. Índice de acidez para o biodiesel, de óleo de amêndoa de Acrocomia aculeata, puro e em contato com os aços carbono e aço carbono galvanizado, ao longo do período de armazenamento

metálicos lixiviados no biodiesel de OAM, técnica que permite a determinação da maioria dos elementos traço em combustíveis na faixa de $\mathrm{mg} \mathrm{kg}^{-1}$ e limites de detecção na faixa de $\mu \mathrm{g} \mathrm{kg}{ }^{-1}{ }^{25} \mathrm{As}$ concentrações de $\mathrm{Fe}, \mathrm{Zn}$ e Mn lixiviados no biodiesel nos ensaios de corrosão foram analisadas por AAS; nenhum desses elementos foi detectado em qualquer das amostras expostas aos aços carbono (concentrações abaixo do limite de detecção, LD), no período de armazenamento investigado.

\section{Caracterização química das barras de aço e taxa da corrosão}

A espectroscopia Mössbauer, usando o isótopo ${ }^{57} \mathrm{Fe}$ como núcleosonda, é uma excelente ferramenta analítica para investigar espécies ferruginosas e a eventual ocorrência de produtos de oxidação nos aços carbono aqui analisados.

Os espectros Mössbauer foram obtidos para as amostras na temperatura ambiente, 298 K (Figura 2; parâmetros hiperfinos correspondentes na Tabela 7), nomeadamente para as barras controle dos aços AC API e AC ASTM, limpas e sem imersão no biodiesel, e para os aços AC API, AC ASTM, AG API e AG ASTM, após os ensaios de imersão estática no biodiesel de OAM.

Espectros também foram obtidos com as amostras na temperatura de $80 \mathrm{~K}$ (Figura 3), exceto para as amostras de aços galvanizados AG API e AG ASTM, pois elas não mostraram linhas de ressonância nas medidas experimentais em $298 \mathrm{~K}$.

Os espectros de todas as amostras mostram um sexteto típico de ferro metálico $\left(\mathrm{Fe}^{0}\right)$ tanto na temperatura ambiente quanto em $80 \mathrm{~K}$. A amostra do aço AC API sem contato com o biodiesel mostra ainda um dupleto central atribuível a $\mathrm{Fe}^{3+}$, provavelmente de óxido de ferro com tamanho de partícula muito pequeno, pois a espécie ferruginosa de origem não ordena magneticamente nem mesmo na temperatura de $80 \mathrm{~K}$. Curiosamente, o dupleto não foi observado nos espectros obtidos para o mesmo aço quando em contato com o biodiesel de OAM.

Os espectros Mössbauer obtidos para o aço AC ASTM, sem contato com o biodiesel, em temperatura ambiente e $80 \mathrm{~K}$, além do sexteto característico de ferro metálico, mostram mais dois sextetos atribuíveis à magnetita $\left(\mathrm{Fe}_{3} \mathrm{O}_{4}\right)$, um para o sítio de coordenação tetraédrico, que acomoda apenas íons $\mathrm{Fe}^{3+}$, e outro para o sítio de coordenação octaédrico, tanto com íons $\mathrm{Fe}^{3+}$ como $\mathrm{Fe}^{2+}$. ${ }^{26}$ Surpreendentemente, o espectro da amostra a $298 \mathrm{~K}$ mostra também um dupleto de $\mathrm{Fe}^{2+}$ com parâmetros hiperfinos compatíveis com os da wüstita $\left(\mathrm{Fe}_{1-\mathrm{x}} \mathrm{O}\right)$. Uma atribuição que pode ser confirmada dos dados da medida com a amostra a $80 \mathrm{~K}$, temperatura em que a wüstita ordena-se magneticamente com um campo magnético hiperfino 35,5 tesla. A ocorrência da wüstita, no entanto, não pode ser interpretada como sendo produto da corrosão do aço, pois a formação dessa espécie ferruginosa não é termodinamicamente favorável à temperatura ambiente. ${ }^{21,27}$ Nenhum modelo pôde, pois, ser formulado para a formação da wüstita, apenas com os presentes dados disponíveis paras os aços das amostras estudadas; seriam necessárias informações mais completas sobre os processos industriais metalúrgicos correspondentes.

As medidas Mössbauer mostram evidências experimentais muito claras de que os aços carbono aqui investigados têm uma tendência a sofrer oxidação quando em contato direto com o ar atmosférico e que, por outro lado, a imersão desses materiais no biodiesel do OAM protege, em alguma extensão, os aços, relativamente à oxidação. É possível que alguma proporção de glicerina residual da reação de transesterificação favoreça a proteção química dos aços, no contato direto com o oxigênio do ar.

As barras de aço AC API, AG API, AC ASTM e AG ASTM quase não apresentavam sinal de ataque corrosivo localizado, tendo uma aparência uniforme. As TCs foram calculadas após os ensaios de imersão estática dos aços e os valores encontrados analisados de acordo com a norma NACE RP $0775,{ }^{16}$ que comumente é expressa em mm ano ${ }^{-1}$, para análise da classificação da taxa de corrosão.

Os ensaios foram feitos em triplicata e os resultados para as taxas de corrosão dos aços carbono são mostrados na Tabela 8.

As TCs encontradas para as barras de aço AC API, AG API, AC ASTM e AG ASTM foram classificadas como baixas, mas, analisando-se os dados da Tabela 8, observa-se que os aços galvanizados tiveram menor TC em relação aos aços não galvanizados, indicando não haver produtos de corrosão de ferro para os aços protegidos com a camada de zinco, como mostraram os dados Mössbauer. Os baixos valores foram, portanto, atribuídos à proteção conferida aos aços pela camada de zinco, ${ }^{11}$ que favoreceu a maior durabilidade desses materiais. Da Tabela 8, a TC do AC API foi maior que a do AC ASTM indicando que aquele aço, quando em contato com o biodiesel de $\mathrm{OAM}$, tendeu a ter maior perda de massa. O biodiesel de OAM em contato com o AC API comparado aos outros biodieseis teve maior tendência em degradar-se ao longo do tempo de armazenamento e 

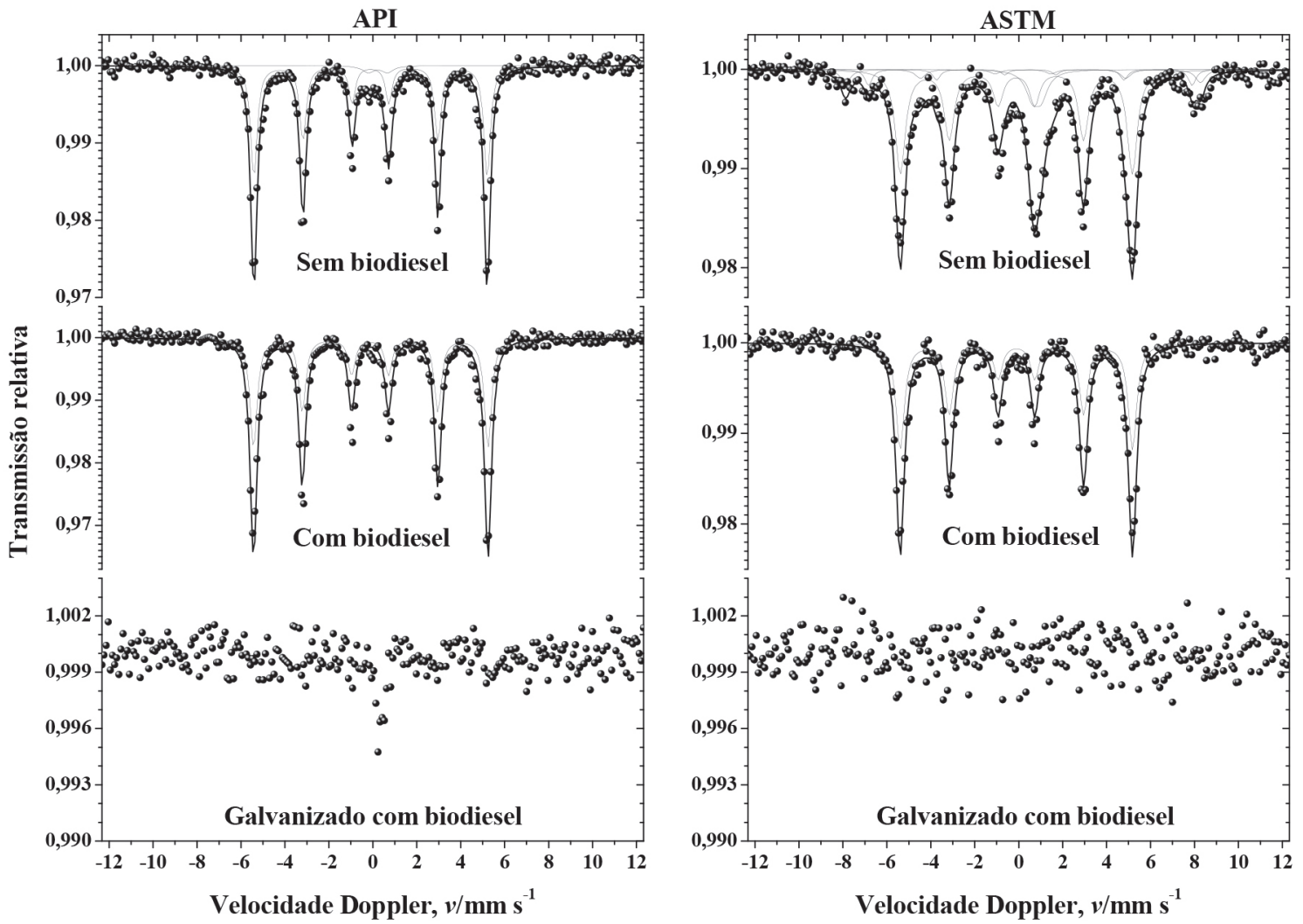

Figura 2. Espectros Mössbauer do ${ }^{57} \mathrm{Fe}$ para as amostras de aços em temperatura ambiente, $298 \mathrm{~K}$

Tabela 7. Parâmetros hiperfinos do ajuste numérico dos espectros Mössbauer do ${ }^{57} \mathrm{Fe}$ para as amostras de aço carbono em temperatura ambiente, $~ 298 \mathrm{~K}$, e $80 \mathrm{~K}$

\begin{tabular}{|c|c|c|c|c|c|c|c|}
\hline Amostra & Temperatura/K & Sítio do Fe & $\delta / \mathrm{mm} \mathrm{s}^{-1}$ & $2 \varepsilon, \Delta / \mathrm{mm} \mathrm{s}^{-1}$ & $\Gamma / \mathrm{mm} \mathrm{s}^{-1}$ & $B_{h j} / \mathrm{T}$ & $A R / \%$ \\
\hline \multirow{4}{*}{$\begin{array}{l}\text { AC API } \\
\text { Sem biodiesel }\end{array}$} & \multirow{2}{*}{298} & $\mathrm{Fe}^{0}$ & $-0,004(2)$ & $0,006(3)$ & $0,355(5)$ & $32,91(1)$ & $91,4(1)$ \\
\hline & & $\mathrm{Fe}^{3+}$ & $0,34(3)$ & $0,9(4)$ & $0,6(2)$ & & $8,6(1)$ \\
\hline & \multirow{2}{*}{80} & $\mathrm{Fe}^{0}$ & $0,090(1)$ & $0,006(3)$ & $0,376(4)$ & $33,32(1)$ & $95,9(1)$ \\
\hline & & $\mathrm{Fe}^{3+}$ & $0,45(2)$ & $0,87(4)$ & $0,38(5)$ & & $4,1(1)$ \\
\hline \multirow{2}{*}{$\begin{array}{l}\text { AC API } \\
\text { Com biodiesel }\end{array}$} & 298 & $\mathrm{Fe}^{0}$ & $-0,007(2)$ & $0,033(3)$ & $0,390(5)$ & $33,07(1)$ & $100,00(9)$ \\
\hline & 80 & $\mathrm{Fe}^{0}$ & $0,101(2)$ & $0,003(4)$ & $0,377(3)$ & $33,81(1)$ & $100,00(6)$ \\
\hline \multirow{8}{*}{$\begin{array}{l}\text { AC ASTM } \\
\text { Sem biodiesel }\end{array}$} & \multirow{4}{*}{298} & $\mathrm{Fe}^{0}$ & $-0,005(3)$ & $-0,001(7)$ & $0,553(9)^{\#}$ & $32,73(2)$ & $71,0(1)$ \\
\hline & & {$\left[\mathrm{Fe}^{3+}\right]_{\mathrm{Mt}}$} & $0,30(3)$ & $0^{*}$ & $0,54(9)$ & $50,1(2)$ & $8,9(1)$ \\
\hline & & $\left\{\mathrm{Fe}^{2,5+}\right\}_{\mathrm{Mt}}$ & $0,63(3)$ & $0^{*}$ & $0,40(8)$ & $45,7(2)$ & $5,7(1)$ \\
\hline & & $\mathrm{Fe}^{2+}$ & $0,93(1)$ & $0,41(3)$ & $0,719(9)^{\#}$ & & $14,4(1)$ \\
\hline & \multirow{4}{*}{80} & $\mathrm{Fe}^{0}$ & $0,095(1)$ & $0,003(3)$ & $0,437(4)^{\#}$ & $33,77(1)$ & $78,9(1)$ \\
\hline & & {$\left[\mathrm{Fe}^{3+}\right]_{\mathrm{Mt}}$} & $0,396(9)$ & $0^{*}$ & $0,37(3)$ & $51,24(7)$ & $8,8(1)$ \\
\hline & & $\left\{\mathrm{Fe}^{2,5+}\right\}_{\mathrm{Mt}}$ & $0,62(2)$ & $0^{*}$ & $0,33(7)$ & $47,8(1)$ & $3,5(1)$ \\
\hline & & $\mathrm{Fe}_{1-\mathrm{x}} \mathrm{O}$ & $1,17(5)$ & $0^{*}$ & $1,004(4)^{\#}$ & $35,7(3)$ & $8,8(1)$ \\
\hline \multirow{2}{*}{$\begin{array}{l}\text { AC ASTM } \\
\text { Com biodiesel }\end{array}$} & 298 & $\mathrm{Fe}^{0}$ & $-0,005(3)$ & $-0,003(6)$ & $0,464(8)$ & $32,78(2)$ & $100,0(1)$ \\
\hline & 80 & $\mathrm{Fe}^{0}$ & $0,103(1)$ & $-0,003(2)$ & $0,424(7)$ & $33,76(2)$ & $100,0(1)$ \\
\hline
\end{tabular}

$\delta=$ deslocamento isomérico relativo ao $\alpha \mathrm{Fe} ; 2 \varepsilon=$ deslocamento quadrupolar; $\Delta=$ desdobramento quadrupolar; $\Gamma=$ largura de linha à meia altura; $B_{h f}=$ campo magnético hiperfino; $A R=$ área subespectral relativa. Os números entre parênteses são incertezas representadas sobre o último algarismo significativo do valor correspondente, estimadas para cada parâmetro, como resultado do ajuste de funções lorentzianas aos dados das linhas de ressonância, por algoritmo não-linear de minimização da soma dos quadrados dos desvios experimentais. " parâmetro fixado durante o ajuste não-linear pelo método dos mínimos quadrados. ${ }^{~ p a r a ̂-~}$ metro restringido durante o ajuste não-linear pelo método dos mínimos quadrados.

um aumento do IA com menor tempo de estocagem, em relação aos outros biodieseis em contato com os outros aços, o que pode ter ocasionado maior TC para o aço não galvanizado. Outros fatores importantes a serem considerados para justificar a classificação das TCs como baixas é a possibilidade de um menor contato do biodiesel e do aço com o ar, que promove a corrosão (os ensaios ocorreram em frascos vedados) e a grande proporção de ésteres metílicos saturados no biodiesel do OAM, que tende a conferir maior estabilidade químico-oxidativa ao biodiesel e menor corrosão aos aços. 


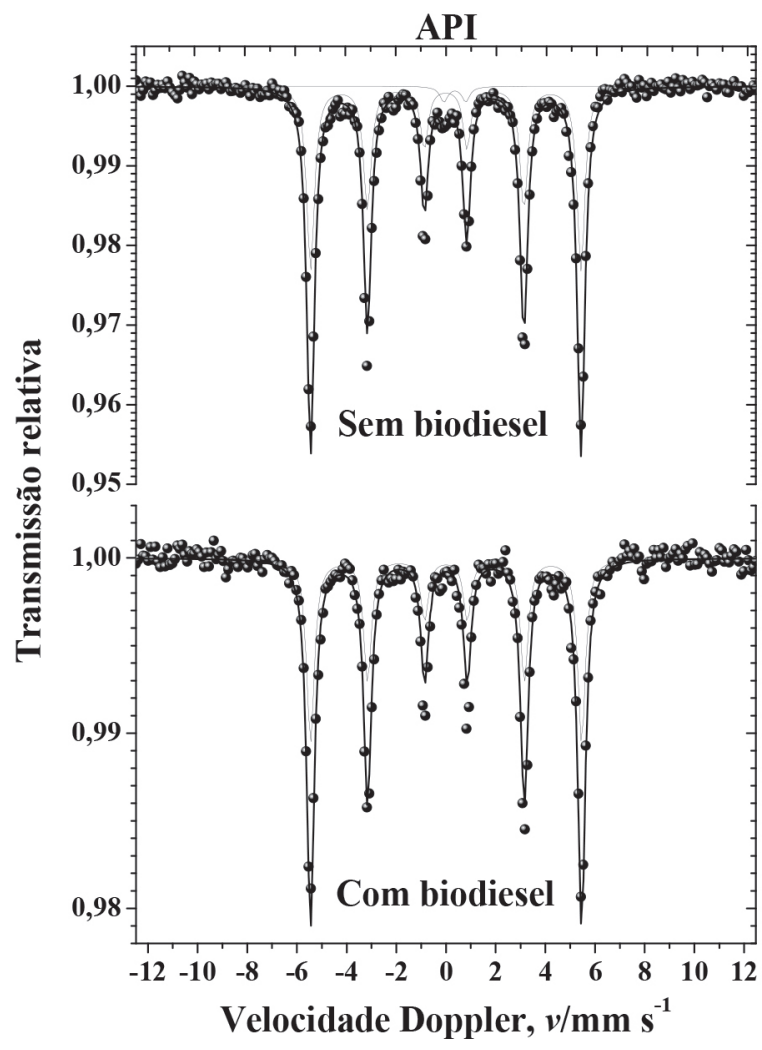

Figura 3. Espectros Mössbauer do ${ }^{57} \mathrm{Fe}$ para as amostras de aços em $80 \mathrm{~K}$

Tabela 8. Resultados da taxa de corrosão dos aços em ensaios de imersão estática em biodiesel de OAM

\begin{tabular}{cc}
\hline Aço & Taxa de corrosão/mm ano $^{-1}$ \\
\hline AC API & 0,024 \\
AG API & 0,016 \\
AC ASTM & 0,022 \\
AG ASTM & 0,015 \\
\hline
\end{tabular}

\section{CONCLUSÃO}

Dos presentes resultados, a produção do OAM é tecnicamente viável, na escala industrial. Embora o óleo precursor apresentasse índice de acidez relativamente elevado, houve boa conversão em ésteres metílicos, via reação de transesterificação dos triacilgliceróis por catálise homogênea, com hidróxido de sódio: 94,34\% de rendimento químico, com aproximadamente $41 \%$ dos ésteres com cadeias moleculares dos ácidos graxos de 8 a 12 carbonos. A propósito, 34,70 massa\% dos ésteres correspondem a laurato de metila e 29,26 massa\% a oleoato de metila. Os ésteres são predominantemente saturados. Os parâmetros físico-químicos confirmam que o biodiesel do OAM está dentro dos limites recomendados pela ANP, com exceção do teor de água, ficando indispensável a otimização da etapa de desidratação.

As médias analisadas com o programa de computador para análise estatística SISVAR indicam que, de forma geral, os biodieseis em contato com os aços AC ASTM e AG ASTM apresentaram comportamento dos ésteres mais semelhante aos ésteres do biodiesel controle. Deduz-se que os aços AC ASTM, AG ASTM e AG API permitem maior estabilidade química dos principais ésteres formadores do biodiesel de macaúba. Ainda que tenha havido alterações das quantidades de ésteres do biodiesel em contato com o AC API, as variações não foram significativas até os 57 dias do experimento. Os ésteres que

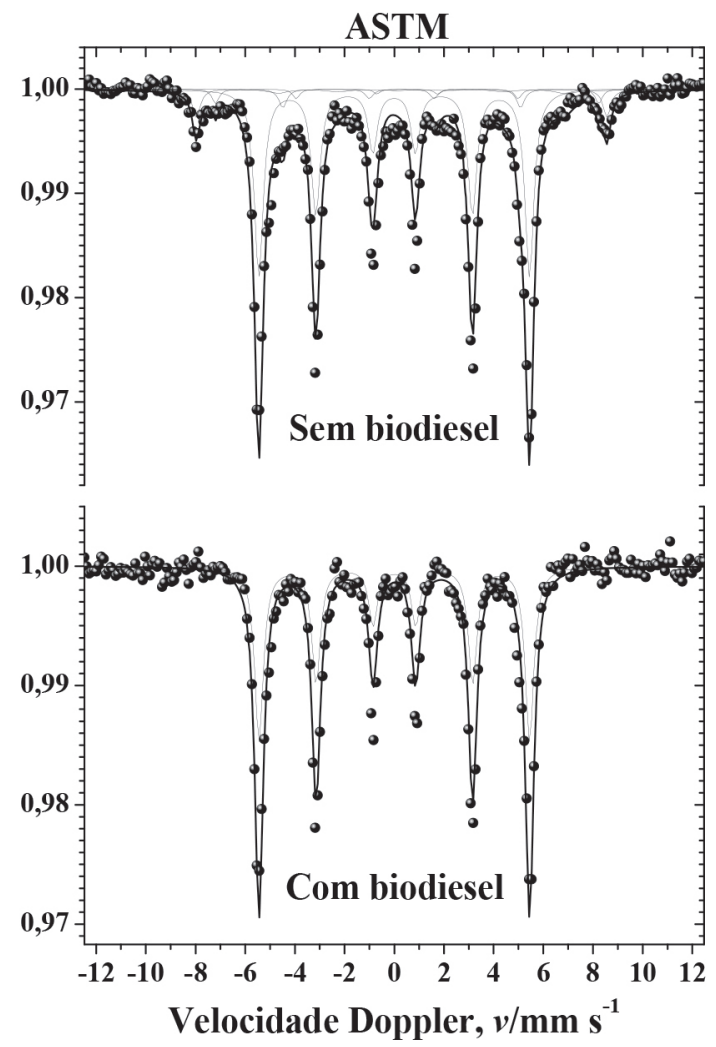

tiveram maior variação de suas concentrações foram o C12:0, C14:0 e o C18:1. Todavia, os testes de médias carecem de correlações com a lixiviação de Fe, Zn e Mn no biodiesel, cujos teores devem ser determinados por técnicas químico-analíticas que alcancem limites de concentrações sensivelmente mais baixos. Mais estudos devem ser realizados para se entender e se correlacionar os mecanismos que causam a instabilidade dos ésteres e suas modificações químicas associadas à lixiviação dos metais majoritários do aço.

Os resultados obtidos por espectroscopia Mössbauer mostraram também que o contato com o biodiesel de OAM confere alguma proteção química aos aços não galvanizados do presente estudo. Os aços sem galvanização imersos no biodiesel foram conservados ao longo do experimento, não tendendo a sofrer corrosão oxidativa, sobretudo pela formação de magnetita $\left(\mathrm{Fe}_{3} \mathrm{O}_{4}\right)$ até os 105 dias de armazenamento. Tal proteção pode ser atribuída especialmente aos ésteres metílicos predominantemente saturados, obtidos da transesterificação do OAM.

As taxas de corrosão encontradas para os aços aqui investigados, segundo classifica a Norma NACE-RP 0775: Preparation, Installation, Analysis, and Interpretation of Corrosion Coupons in Oilfield Operations, podem ser classificadas como baixas.

\section{MATERIAL SUPLEMENTAR}

As equações da reta obtidas por regressão linear e os coeficientes de determinação $\left(\mathrm{r}^{2}\right)$ correspondentes para cada cátion metálico analisado por AAS são mostrados na Tabela 1S; os ésteres metílicos após a transesterificação do OAM e os teores correspondentes constam na Tabela $2 \mathrm{~S}$; as concentrações médias dos ésteres, em $\mathrm{mg} \mathrm{mL}^{-1}$, do biodiesel puro e em contato com os aços ao longo dos períodos de estocagem são mostradas nas Tabelas 3S (C8:0), 4S (C10:0) e 5S (C18:0), disponíveis em http://www.quimicanova.sbq.org.br, em formato PDF, com acesso livre. 


\section{AGRADECIMENTOS}

À Fundação de Amparo à Pesquisa do Estado de Minas Gerais (FAPEMIG; concessão \# CEX - PPM-00412-15) e ao Conselho Nacional de Desenvolvimento Científico e Tecnológico (CNPq; concessões \# 304958/2017-4 e \# 313431/2017-5), pelo apoio financeiro. JDF é bolsista PVNS/CAPES na UFVJM. À USIMINAS (Ipatinga, MG), em particular, à E. P. S. Pimenta, por toda especial atenção e interesse no trabalho, pelo provimento das amostras de aço carbono. A D. J. S. Viana, pelo tratamento estatístico dos dados, P. C. R. Andrade, pela ajuda na compreensão dos resultados estatísticos e a A. J. S. Viana, pelas medidas de AAS.

\section{REFERÊNCIAS}

1. Sundus, F.; Fazal, M. A.; Masjuki, H. H.; Renewable Sustainable Energy Rev. 2017, 70, 399.

2. Dias, H.; Sbari, C.; Corrosão \& Proteção 2009, $28,9$.

3. Zuleta, E. C.; Baena, L.; Rios, L. A.; Calderón, J.; J. Braz. Chem. Soc. 2012, 23,12.

4. Deyab, M. A.; Keera, S. T.; J. Taiwan Inst. Chem. Eng. 2016, 68, 187.

5. Mobarak, H. M.; Mohamad, E. N.; Masjuki, H. H.; Kalam, M. A.; Mahmud, K.; Habibullah, M.; Ashraful, A.; Renewable Sustainable Energy Rev. 2014, 33, 34.

6. Monte, I. R.; Dissertação de Mestrado, Universidade de São Paulo, Brasil, 2013.

7. Luciano, M. A.; Dissertação de Mestrado, Universidade Federal de Minas Gerais, Brasil, 2011.

8. Ambrozin, A. R. P.; Kuri, S. E.; Monteiro, M. R.; Quim. Nova 2009, 32, 1910.

9. Fazal, M. A.; Sazzad, B. B.; Haseeb, A. S. M. A; Masjuki, H. H.; Energy Convers. Manage. 2016, 122, 290.

10. Ferrari, R. A.; Souza, W. L.; Quim. Nova 2009, 32, 106.

11. Cedrim, F. A.; Almeida, V. L. S.; Souza, C. A. C.; Jesus, M. D.; Ribeiro, D. V.; Rev. IBRACON Estrut. Mater. 2016, 9, 595.
12. ASTM International. ASTM G1-03 (2011) - Prática Padrão para Preparação, Limpeza e Avaliação de Amostras de Teste de Corrosão. West Conshohocken: ASTM International, 2011.

13. American Society for Testing and Materials - ASTM, ASTM D445-06 - Standard Test for Kinematic Viscosity.

14. Instituto Adolfo Lutz. Normas Analíticas do Instituto Adolfo Lutz, v. 1: Métodos químicos e físicos para análise de alimentos, $3^{\mathrm{a}}$ ed., IMESP: São Paulo, 1985. p. 232.

15. Ferreira, D. F.; Ciênc. agrotec. 2011, 35, 1039.

16. NACE - NACE RP-0775 - Preparation, Installation, Analysis, and Interpretation of Corrosion Coupons in Oilfield Operations. Houston: NACE, 2005.

17. Ministério de Minas e Energia, Agência Nacional do Petróleo, Gás Natural e Biocombustíveis, Resolução No 14, de 11 de maio de 2012. http://www.lex.com.br/legis_23365001_RESOLUCAO_N_14_DE_11_ DE_MAIO_DE_2012.aspx, acessada em março de 2019.

18. Fernandes, D. M.; Sousa, R. M. F.; Oliveira, A.; Morais, S. A. L.; Richter, E. M.; Muñoz, R. A. A.; Fuel 2015, 146, 75.

19. Fernandes, D. M.; Montes, R. H. O.; Almeida, E. S.; Nascimento, A. N.; Oliveira, P. V.; Richter, E. M.; Muñoz, R. A. A.; Fuel, 2013, 107, 609.

20. http://bvsms.saude.gov.br/bvs/saudelegis/anvisa/2005/ rdc0270_22_09_2005.html, acessada em março de 2019.

21. Glaria, A.; Kahna, M. L.; Chaudret, B.; Lecantec, P.; Casanovec, M. J.; Mater. Chem. Phys. 2011, 129, 605.

22. Silva, W. L. G.; Dissertação de Mestrado, Universidade Estadual de Campinas, Brasil, 2015.

23. Leung, D. Y. C.; Koo, B. C. P.; Guo, Y.; Bioresour. Technol. 2006, 97, 250.

24. Silva, C. M. R.; Dissertação de Mestrado, Universidade de São Paulo, Brasil, 2008.

25. Jesus, A.; Dissertação de Mestrado, Universidade Federal do Rio Grande do Sul, Brasil, 2008.

26. Oliveira, D. S.; Fonseca, X. D. S.; Farias, P. N.; Bezerra, D. S.; Pinto, C. H. C.; Souza, L. D.; Holos 2012, 28, 49.

27. Gavarri, J. R.; Carel, C.; Prog. Solid State Chem. 2019, 53, 27. 